\title{
A mitochondrial mechanism is involved in apoptosis of Robertsonian mouse male germ cells
}

\author{
Valeria Merico, Gabriela Diaz de Barboza ${ }^{1}$, Chiara Vasco, Ruben Ponce ${ }^{1,2}$, Valeria Rodriguez ${ }^{1}$, \\ Silvia Garagna and Nori Tolosa de Talamoni ${ }^{1}$ \\ Dipartimento di Biologia Animale, Università degli Studi di Pavia, Piazza Botta, 9-10, I-27100 Pavia, Italy, \\ ${ }^{1}$ Bioquimica y Biologia Molecular, Facultad de Ciencias Medicas and ${ }^{2}$ Quimica y Fisica Biologicas, Facultad de \\ Odontologia, Universidad Nacional de Cordoba, 5000 Cordoba, Argentina
}

Correspondence should be addressed to S Garagna; Email: silvia.garagna@unipv.it

\begin{abstract}
The aim of this study was to determine whether the intrinsic mechanism of apoptosis is involved in the death of germ cells in Robertsonian ( $R b$ ) heterozygous adult male mice. Testes from 5-month-old Rb heterozygous CD1 $\times$ Milano II mice were obtained and compared with those from homozygous CD1 $(2 n=40)$ and Milano II $(2 n=24)$ mice. For histological evaluation of apoptosis, TUNEL labelling and

immunohistochemistry were used to localise Bax and cytochrome $c$. Expression of calbindin $D_{28 k}(C B)$, an anti-apoptotic molecule, was also analysed by immunohistochemistry and immunoblotting. Testicular ultrastructure was visualised by electron microscopy. Morphology and cell associations were abnormal in the $\mathbf{R b}$ heterozygous seminiferous epithelium. An intense apoptotic process was observed in tubules at stage XII, mainly in metaphase spermatocytes. Metaphase spermatocytes also showed Bax and cytochrome $c$ redistributions. Mitochondria relocated close to the paranuclear region of spermatocytes. CB was mainly expressed in metaphase spermatocytes, but also in pachytene spermatocytes, spermatids and Sertoli cells at stage XII. The co-localisation of CB and TUNEL labelling was very limited. Sixty per cent of metaphase spermatocytes were apoptotic and calbindin negative, while $40 \%$ were calbindin positive without signs of apoptosis. Ten per cent of the Bax- and cytochrome $c$-positive cells were also calbindin positive. These data suggest that apoptosis of the germ cells in heterozygous mice occurs, at least in part, through a mitochondrial-dependent mechanism. Calbindin overexpression might prevent or reduce the apoptosis of germ cells caused by Rb heterozygosity, which could partially explain the subfertility of these mice.
\end{abstract}

Reproduction (2008) 135 797-804

\section{Introduction}

Spermatogenesis is a complex process by which male germ cells mature from spermatogonia via spermatocytes and spermatids to spermatozoa and involves a controlled balance between cell proliferation and death (Lizama et al. 2007). Infertility or testicular disorders may appear when this balance is deregulated (Francavilla et al. 2000, 2002, Eguchi et al. 2002).

There are many different, poorly understood causes of deregulation of cell proliferation/cell death during spermatogenesis. However, a normal karyotype is an essential prerequisite for proper spermatogenesis as shown by the detrimental effects of structural rearrangements of the karyotype on this process (Redi et al. 1985, Wallace et al. 2002). The extent of the impairment of spermatogenesis depends on various factors such as the type and number of fusions, the configuration of diakinesis during meiosis and genic incompatibilities. In Robertsonian (Rb) heterozygous mice, Merico et al. (2003) found a high percentage (up to $59 \%$ ) of defective seminiferous tubules in 5-month-old animals in which the typical cell-to-cell associations were almost unrecognisable. In these animals, the spermatid/ spermatocyte ratio was as low as 1.4 when compared with the expected 4.0. Massive germ cell depletion was detected at each step of germ cell differentiation in both meiotic and post-meiotic germ cells indicating cell death. The impairment of spermatogenesis exerted by $\mathrm{Rb}$ heterozygosity was found to be partially relieved with time because the percentage of defective tubules was lower, and germ cell survival and sperm morphology better in 7-month-old mice than in 3- and 5-month-old animals. Eaker et al. (2001) demonstrated a high frequency of misaligned, condensed chromosomes in their Rb heterozygous mice, which could account for a significant proportion of the apoptotic spermatocytes suggesting a checkpoint process that identifies aberrant meiosis, although this mechanism would not be efficient enough to avoid the high frequency of gametic aneuploidy.

During spermatogenesis, spermatogonia undergo several cell divisions and spermatocytes divide twice to build the germ cell population of the testis (Russell et al. 2002). Some authors have found that immature spermatogonia show features of apoptosis, while more mature 
spermatocytes do not (Allan et al. 1987, Russell 1999); however, others have found that in the first wave of spermatogenesis primarily mid-pachytene spermatocytes die by apoptosis (Jahnukainen et al. 2004). Cell death is, therefore, a normal process during spermatogenesis, limiting the number of germ cells to ensure that Sertoli cells can provide enough nutrients to nurture the continuous generation of germ cells (Lee et al. 2006). The Fas system has been shown to be involved in the regulation of germ cell apoptosis in the rat testis. Through binding to its ligand, FasL, Fas promotes activation of caspase-8, which proteolytically activates executive caspases that ultimately kill the cells. Another set of caspases, involved in the intrinsic apoptotic pathway, has recently been reported to be involved in spermatocyte apoptosis from the first round of spermatogenesis in the rat (Lizama et al. 2007). When apoptosis in pachytene spermatocytes occurs as a result of stimuli such as heat or hormone deprivation, it appears that only the intrinsic pathway is stimulated (Sinha Hikim etal. 2003). A caspaseindependent mechanism triggered by calpain activation is another mechanism that has been suggested to be involved in germ cell apoptosis (Coureuil et al. 2006). Some members of the p53 family and high $\left[\mathrm{Ca}^{2+}\right]_{i}$ also appear to be important regulators of apoptotic death in spermatogenic cells (Mishra et al. 2006, Petre-Lazar et al. 2007). However, the pathways leading to apoptosis of germ cells in the testes from the Rb heterozygous mice remain elusive.

Data from studies employing extrinsic modulators of $\mathrm{Ca}^{2+}$ homeostasis have suggested that the increment in $\left[\mathrm{Ca}^{2+}\right]_{i}$ is a signal sufficient to produce apoptosis. Calpains are frequently activated in apoptosis models involving enhanced $\left[\mathrm{Ca}^{2+}\right]_{\mathrm{i}}$. Furthermore, the modulated expression of calcium-binding proteins, such as calbindin $\mathrm{D}_{28 \mathrm{k}}(\mathrm{CB})$ and others, can confer protein protection against apoptotic stimuli (Mathiasen et al. 2002). CB is a protein that was originally discovered in chick intestine (Wasserman \& Taylor 1966), where its expression is vitamin $\mathrm{D}$ dependent. CB expression is low in both mice and chick testes and is vitamin D independent and dependent respectively (Walters et al. 1991, Inpanbutr et al. 1996). Christakos \& Liu (2004) showed that CB has a major role in different cell types in protecting against cell death by preventing calcium-mediated mitochondrial damage and the subsequent release of cytochrome $c$.

Using a mouse model with reduced fertility, we studied whether the intrinsic mechanism of apoptosis is involved in the partial arrest of spermatogenesis caused by the heterozygous Rb translocations. We also analysed the expression of $\mathrm{CB}$ as a protective mechanism against apoptosis.

\section{Results}

\section{Rb heterozygous mice exhibit high apoptosis of germ cells}

We used 5-month-old mice in our study since Merico et al. (2003) had previously shown that the spermatogenic process is more impaired in Rb heterozygous mice of that age than in 3- or 7-month-old animals. The testicular histology of CD1 and Mil II mice had a normal appearance while heterozygous CD1 $\times$ Mil II (hereafter also named $\mathrm{Rb}$ heterozygous) mice showed a large proportion of defective seminiferous tubules with atypical cellular associations and severe germ cell loss, confirming previous findings (Merico et al. 2003). In order to estimate apoptosis we employed the TUNEL assay, which is a marker of DNA fragmentation. Figure 1 shows that TUNEL-positive cells were scarce in the seminiferous tubules from CD1 or Mil II mice, while TUNEL staining was strong in seminiferous tubules from $\mathrm{Rb}$ heterozygous mice. The percentage of TUNELpositive tubule cross sections was significantly higher in the testes of $\mathrm{Rb}$ heterozygous mice than in those of either CD1 or Mil II animals (Table 1). Most of the tubules showing apoptotic cells were at stage XII, involving germ cells in both metaphases I and II. The mean number of TUNEL-positive cells/tubule section was seven- to ninefold higher in Rb heterozygous mice than in the Mil II or CD1 mice, indicating that massive cell death of germ cells occurred by apoptosis in the Rb heterozygotes. No significant differences were found in either the percentage of TUNEL-positive tubule cross sections or in the mean number of TUNEL-positive cells/tubule section between CD1 and Mil II mice, but these latter exhibited higher levels of TUNEL-positive tubules (Table 1).

\section{Mitochondria move into paranuclear areas of sperma- tocytes in Rb heterozygous mice}

Mitochondria conglomerated in the area close to the nuclear periphery in spermatocytes of Rb heterozygous mice whereas the mitochondria were sparsely distributed in CD1 and Mil II spermatocytes (Fig. 2). The movement of mitochondria towards the nuclear periphery of the
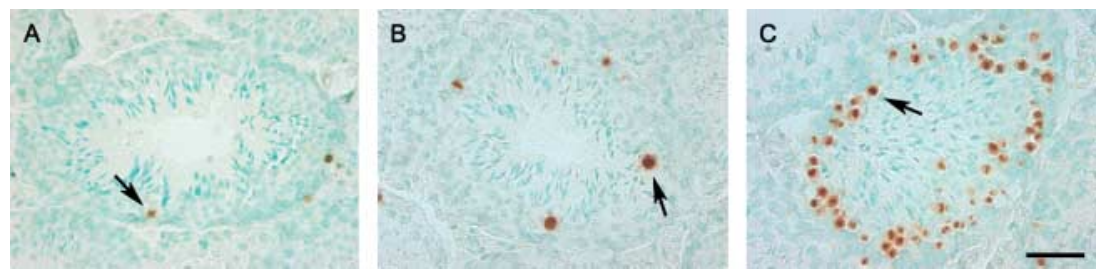

Figure 1 TUNEL labelling in seminiferous tubules from (A) CD1, (B) Mil II and (C) CD1 ×Mil II mice. (B) shows a section of Mil II seminiferous tubule in which the highest number of TUNEL-positive metaphase spermatocytes was detected. The arrows indicate metaphase spermatocytes from tubules at stage XII. Bar $=50 \mu \mathrm{m}$. 
Table 1 CD1 $\times$ Mil II mice exhibit greater TUNEL labelling of germ cells in the seminiferous tubules than that of their parental strains.

\begin{tabular}{lccc}
\hline Karyotype group & $\mathbf{2 n}$ & $\begin{array}{c}\text { \% TUNEL-positive cross-sectioned } \\
\text { tubules }( \pm \text { s.E.M.) }\end{array}$ & $\begin{array}{c}\text { Mean number of TUNEL-positive cells/tubule } \\
\text { cross section }( \pm \text { s.E.M.) }\end{array}$ \\
\hline CD1 homozygote & 40 & $8.23 \pm 1.56$ & $3.17 \pm 0.23$ \\
Mil II homozygote & 24 & $16.56 \pm 5.34$ & $4.33 \pm 0.32$ \\
CD1 XMil II Rb heterozygote & 32 & $37.19 \pm 3.37^{*}$ & $27.34 \pm 2.45^{\dagger}$ \\
\hline
\end{tabular}

Rb, Robertsonian; S.E.M., standard error. ${ }^{*} P=0.004$ versus both $\mathrm{CD} 1$ and Mil II; ${ }^{+} P<0.001$ versus both CD1 and Mil II.

spermatocytes of $\mathrm{Rb}$ heterozygotes may be considered an indication of apoptosis. In fact, mitochondrial redistribution has been observed in apoptotic cells in the mouse testis after induction of apoptosis (Vera et al. 2004). Acrosome malformation, irregularities of the nuclear membrane of both spermatocytes and spermatids and irregularly shaped cells were also found in $\mathrm{Rb}$ heterozygous germ cells (data not shown).

\section{Bax and cytochrome c are involved in the apoptotic mechanism: $C B$ is overexpressed in the damaged tubules}

Given the ultrastructural changes in the germ cells, we hypothesised that the mitochondrial pathway might be involved in the apoptosis of spermatogenic cells. To demonstrate this, we examined, by immunocytochemistry, the localisation of Bax, a pro-apoptotic molecule that moves from a cytoplasmic to a paranuclear localisation, triggering cytochrome $c$ release from the mitochondria. In addition, we also studied cytochrome $c$ localisation. As shown in Fig. 3, there was intense staining for Bax and cytochrome $c$ in the cytoplasm and nuclei of different testicular germ cells from $\mathrm{Rb}$ heterozygous mice: this is an indicator that the intrinsic apoptotic mechanism is involved in the death of the germ cells. Redistributions of Bax and cytochrome $c$ occurred in the same defective seminiferous tubules that showed TUNEL staining. This redistribution was not accompanied by an increase in protein expression, as judged by Western blots, which showed that the amount of Bax or cytochrome $c$ protein in the testis did not differ between the three groups of animals (Fig. 4).

By contrast, $\mathrm{CB}$, an anti-apoptotic protein that can prevent or block apoptotic death, was expressed to a much greater extent in the Rb heterozygous testis than in the CD1 and Mil II testes, as shown by Western blot analysis (Fig. 4). Western blotting revealed two bands of CB expression (28 and $56 \mathrm{kDa}$ ), indicating that this protein dimerises in the mouse testis. Dimerisation of CB has already been reported to occur in other tissues (Pochet et al. 1989, Luu et al. 2004). The amount of both CB monomer and dimer present in the testis of Rb heterozygotes was three- and two-fold higher respectively than that in CD1 and Mil II testes. As shown by TUNEL staining for apoptotic cells, CB was mainly localised in tubules at stage XII (Fig. 3). In Rb heterozygous testis, CB reactivity was shown in $2.74 \%$ of spermatocytes/tubule section, $56.66 \%$ of spermatocytes in metaphase/tubule section, $14.19 \%$ of spermatids/tubule section and $8.95 \%$ of Sertoli cells/tubule section. Only spermatids (2-3\%/tubule section) were $\mathrm{CB}$ positive in the testis from CD1 or Mil II mice. Co-localisation of CB and TUNEL staining was limited in all three groups of animals. Co-localisation of CB/TUNEL, CB/Bax and $\mathrm{CB} /$ cytochrome $C$ was almost absent in the testis from $\mathrm{CD} 1$ or Mil II mice. In Rb heterozygous mice, colocalisation of $\mathrm{CB} / \mathrm{Bax}, \mathrm{CB} / \mathrm{cy}$ tochrome $c$ and $\mathrm{CB} / \mathrm{TUNEL}$ was observed in respectively $9.99 \% \pm 3.13,10.61 \% \pm$ 1.94 and $3.01 \% * \pm 1.10$ of cells $(* P<0.05$ versus $\mathrm{CB} / \mathrm{Bax}$ and $\mathrm{CB} /$ cytochrome $C$; Table 2). Therefore, among those cells showing co-localisation, $\mathrm{CB} / \mathrm{Bax}$ and $\mathrm{CB} /$ cytochrome c co-localisation was more frequent than $\mathrm{CB} / \mathrm{TUNEL}$ co-localisation. In brief, the percentage of cells showing $\mathrm{CB}$ expression and DNA fragmentation was very low in comparison with the percentage of cells in which $\mathrm{CB}$ and Bax or CB and cytochrome $c$ were co-expressed. The rest of the CB-positive cells did not show either TUNEL staining or Bax or cytochrome $c$ reactivity.

\section{Spermatocytes in metaphase are the apoptotic cells in the seminiferous tubules of $R b$ heterozygous mice: $C B$ is overexpressed in metaphase spermatocytes}

Bax, cytochrome $c$ and TUNEL staining were mainly detected in metaphase spermatocytes at stage XII of the cycle of the seminiferous epithelium in Rb heterozygous testis (Table 2). Bax was practically absent in other cell types. Cytochrome $c$ also appeared in $2.5 \%$ of pachytene spermatocytes, $11 \%$ of spermatids and $11 \%$ of Sertoli cells/tubule section whereas TUNEL reactivity was detected in only $3 \%$ of pachytene spermatocytes/tubule section. In Rb heterozygous mice, $\mathrm{CB}$ expression was
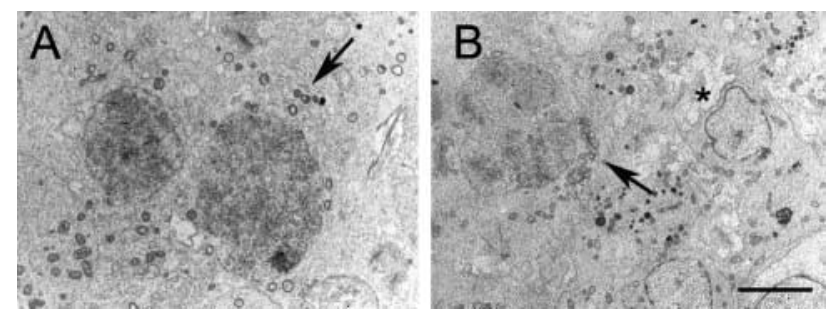

Figure 2 Electron microscopy pictures of male germ cells from (A) CD1 and (B) CD1 $\times$ Mil II mice. The arrow in (A) indicates sparse mitochondria within a spermatocyte and the arrow in (B) indicates a conglomeration of mitochondria close to the nucleus of a spermatocyte. The asterisk indicates a defective acrosome in a spermatid. Bar $=5 \mu \mathrm{m}$. 

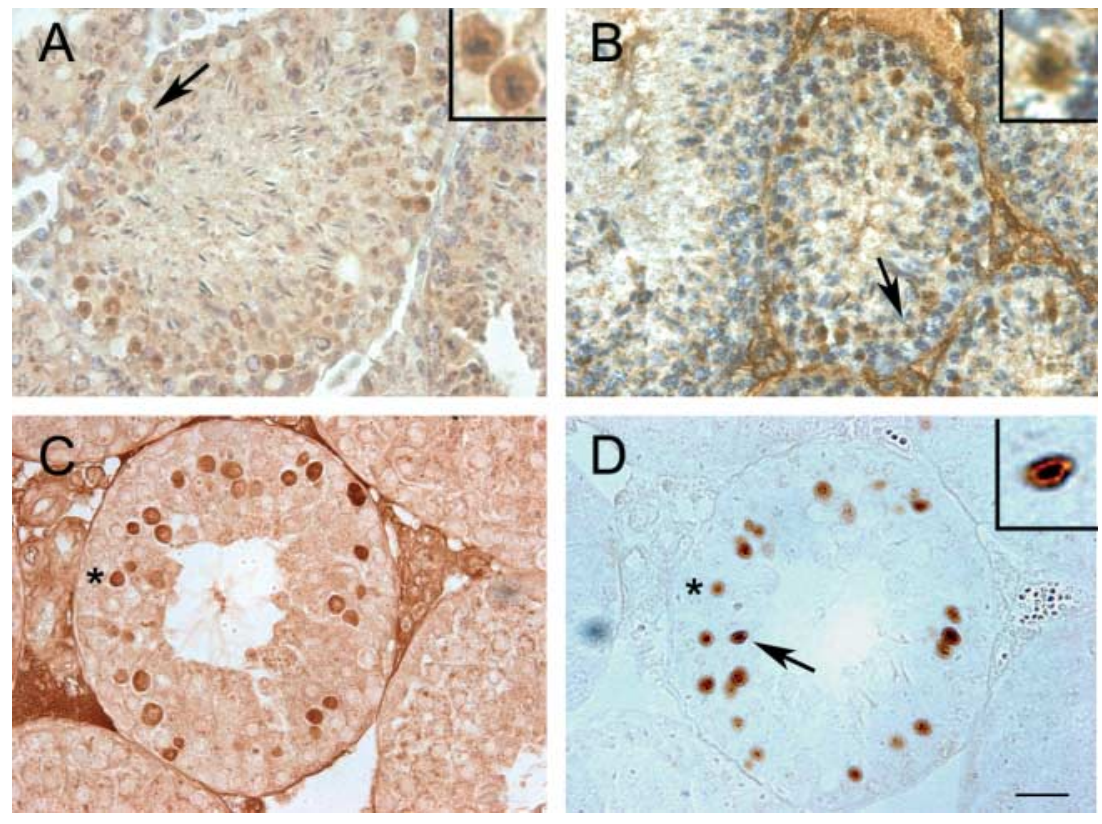

Figure 3 Seminiferous tubules at stage XII from CD1 $\times$ Mil II mice showing (A) Bax, (B) cytochrome $c_{,}(\mathrm{C})$ calbindin $\mathrm{D}_{28 \mathrm{k}}$ and (D) TUNEL staining. Most positive cells are metaphase spermatocytes (arrows) as shown in the insets. The asterisk indicates co-localisation of calbindin and TUNEL labelling of a metaphase spermatocyte. $\mathrm{Bar}=50 \mu \mathrm{m}$. also much higher in metaphase spermatocytes than in other cells from the testis (see above). Forty per cent of metaphase spermatocytes/tubule sections were only $\mathrm{CB}$ positive. The remaining $60 \%$ of metaphase spermatocytes did not show CB reactivity but were TUNEL positive, indicating that they were dying by apoptosis. It is possible that the $40 \%$ of cells that expressed CB were not committed to cell death. It may be that $\mathrm{Rb}$ rearrangements triggered $\mathrm{CB}$ expression in spermatocytes in metaphase in the mouse testis. DNA fragmentation barely occurred in those cells in which $C B$ was expressed. However, in the early stages of apoptosis, CB was associated with Bax and cytochrome $c$ expressions, albeit to a limited extent. In fact, only $10 \%$ of Bax- and cytochrome c-positive cells also expressed CB. The number of cells showing Bax, cytochrome $c$ and TUNEL labelling was very low in CD1 and Mil II testes, and such cells were scattered along the 12 stages of the seminiferous epithelium. The very few positive cells, ranging from 1 to 5 per tubule section, were found at late stage XII or early stage I and they did not express CB. Interestingly, they were all metaphase spermatocytes. The paucity of cells positive for Bax and cytochrome $c$ indicates that relocation of these proteins is very limited. Likewise, the expression of $\mathrm{CB}$ was very low in $\mathrm{CD} 1$ and Mil II germ cells.

\section{Discussion}

The purpose of this study was to determine whether the intrinsic mechanism of apoptosis is involved in the death of germ cells in the testis of Rb heterozygous mice. Our findings clearly show that testis from Rb heterozygous mice exhibits intense apoptosis of germ cells, which is accompanied by the redistributions of Bax and cytochrome $c$. The expression of these proteins, as revealed by Western blotting, was similar to that in CD1 or Mil II mouse testis, indicating that the synthesis of these two pro-apoptotic molecules in Rb heterozygous mice is not greater than that in the other two groups of animals. Therefore, Bax redistribution might be responsible for the release of cytochrome $c$ from the mitochondria, which, through several steps, would finally promote DNA fragmentation. It has been shown that the insertion of Bax into mitochondrial membranes is involved in the release of cytochrome $c$ from the mitochondrial intermembrane space into the cytosol in heat-induced testicular germ cell death (Vera et al. 2004) and in the

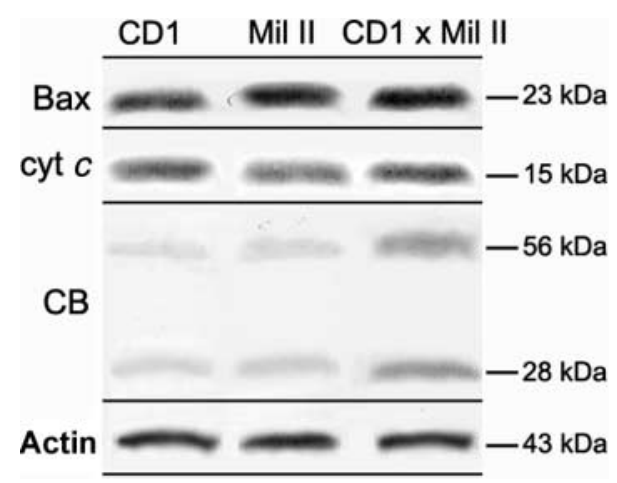

Figure 4 Representative Western blots obtained using anti-Bax, anticytochrome $c$ and anti-calbindin $\mathrm{D}_{28 \mathrm{k}}$ antibodies on whole homogenates (10 $\mu$ g protein) of testis from CD1, Mil II and CD1 $\times$ Mil II mice. Anti-actin antibody was used to detect the housekeeping protein. The molecular weights were calculated by comparison with molecular weight markers run simultaneously with the protein samples. Calbindin $\mathrm{D}_{28 \mathrm{k}}$ presents two bands, one of $28 \mathrm{kDa}$ (monomer) and the other of $56 \mathrm{kDa}$ (dimer). 
Table 2 Frequency of metaphase spermatocytes at stage XII positive for the apoptotic markers studied and for calbindin $\mathrm{D}_{28 \mathrm{k}}$ and their co-localisation.

\begin{tabular}{|c|c|c|c|c|}
\hline \multirow[b]{2}{*}{ Karyotype group } & \multicolumn{4}{|c|}{ Percentage of metaphase spermatocytes/tubule cross section showing co-localisation ( \pm S.E.M.) } \\
\hline & CB/Bax & & e $c$ & CB/TUNEL \\
\hline \multirow[t]{3}{*}{ CD1 $1 \times$ Mil II Rb heterozygote } & $9.99 \pm 3.13$ & & & $3.01 \pm 1.10^{*}$ \\
\hline & \multicolumn{4}{|c|}{ Percentage of positive metaphase spermatocytes/tubule cross section ( \pm S.E.M.) } \\
\hline & Bax & Cytochrome $C$ & TUNEL & $\mathrm{CB}$ \\
\hline CD1 $\times$ Mil II Rb heterozygote & $78.95 \pm 7.14$ & $64.14 \pm 10.24$ & $63.48 \pm 8.78$ & $56.66 \pm 5.81$ \\
\hline
\end{tabular}

$\mathrm{Rb}$, Robertsonian; S.E.M., standard error; $\mathrm{CB}$, Calbindin $\mathrm{D}_{28 \mathrm{k}} \cdot{ }^{*} P<0.05$ versus $\mathrm{CB} / \mathrm{Bax}$ and $\mathrm{CB} / \mathrm{cytochrome} c$.

apoptotic process of the first round of rat spermatogenesis (Lizama et al. 2007). Moreover, the relocation of mitochondria to the paranuclear area in spermatocytes from $\mathrm{Rb}$ heterozygous mice is another indication that these organelles are involved in the apoptosis of germ cells, which has been also demonstrated in heat-induced germ cell death (Vera et al. 2004). Thus, our study shows that the intrinsic apoptotic pathway is involved in the death of testicular germ cells triggered by karyotype rearrangements. Other apoptotic mechanisms were not explored, but cannot be excluded. It has been reported that Fas/FasL is involved in spermatogenic cell death during development, adulthood and after toxic exposure (Mishra et al. 2006). Calpain and the p53 subfamily have also been reported to be involved in male germ cell death (Coureuil et al. 2006, Petre-Lazar et al. 2007).

Most of the DNA fragmentation in Rb heterozygous testis was observed in tubules at stage XII, during which spermatocytes undergo meiotic divisions, in agreement with the previous data showing that the frequency of cell death is higher in this stage. Although apoptosis of male germ cells was significantly higher in Rb heterozygous mice than in CD1 or Mil II mice, most DNA fragmentation occurred mainly in metaphase spermatocytes in all three groups of animals. Eaker et al. (2001) have also reported increased apoptosis in metaphase spermatocytes with misaligned chromosomes in other Rb heterozygous mice $(2 n=36)$, suggesting that a spindle checkpoint mechanism identifies aberrant meiosis. Apoptotic metaphase spermatocytes at stage XII were also found in the testis of $M / h 1^{-1-}$ mice (Eaker etal. 2002). Our study further supports the idea that in metaphase spermatocytes at stage XII a checkpoint mechanism is active, which might be activated in response to meiotic defects.

To maintain testicular homeostasis, pro-survival and pro-apoptotic molecules work together, regulating the extent of apoptosis to produce a supply of high-quality gametes (Mishra et al. 2006). As reported, the quality of male gametes is poor in Rb heterozygous mice, and these mice are subfertile (Redi et al. 1984, Hauffe \& Searle 1998, Wallace et al. 2002). Therefore, some antiapoptotic mechanisms in germ cells must be 'turned on' to limit apoptosis. Among the various apoptotic molecules, $\mathrm{CB}$ has been suggested to protect different cell types against apoptotic cell death induced by both calcium-independent and calcium-dependent pathways (Christakos \& Liu 2004). In our study, we have demonstrated that CB is overexpressed in Rb heterozygous testis, with maximal expression in metaphase spermatocytes. $C B$ overexpression occurs at stage XII, during which TUNEL labelling is also maximal. However, co-localisation of TUNEL labelling and CB is very limited. Sixty per cent of metaphase spermatocytes die by apoptosis and $40 \%$ of them exhibit high expression of $\mathrm{CB}$, without signs of DNA apoptosis. Only $3 \%$ of metaphase spermatocytes show simultaneous apoptosis and CB expression. These data suggest that $\mathrm{CB}$ overexpression might protect against spermatogenic apoptosis. The concomitant presence of CB- or TUNEL-positive cells at stage XII in the same tubule section suggests a potential, immediate surveillance mechanism for preventing cell death, which has rapidly triggered the expression of $\mathrm{CB}$.

Whether CB arrests mitochondrial apoptosis before the onset or during the apoptotic process remains unknown. Co-localisation of CB with molecules involved in the early steps of apoptosis, such as Bax or cytochrome $c$, could indicate that $\mathrm{CB}$ expression either might not be sufficient to block the already initiated apoptosis or might block apoptosis downstream of cytochrome $c$ release. In fact, it has been found that CB is capable of directly inhibiting caspase-3 in MC3T3-E1 osteoblastic cells after treatment with tumour necrosis factor- $\alpha$ (Bellido et al. 2000). In pancreatic $\beta$-cell lines, CB protects against cytokineinduced $\beta$-cell death by buffering calcium, preventing mitochondrial damage and inhibiting the generation of oxygen free radicals (Rabinovitch et al. 2001).

The CB overexpression not only occurs in metaphase spermatocytes but also in other germ cells and Sertoli cells. It is well known that Sertoli cells provide structural support, create an immunological barrier and nourish cells through secretory products (Yuan et al. 2006). Germ cell-Sertoli cell interactions during spermatogenesis have been described, but the molecules regulating these interactions have yet to be identified (Saunders 2003). Further studies are required to determine whether CB expressed in Sertoli cells acts as an anti-apoptotic molecule for these cells themselves or it is a secretory product to protect germ cells from apoptosis. 
In summary, $\mathrm{Rb}$ heterozygous mice present intense apoptosis of germ cells mediated, at least in part, by a mitochondrial apoptotic mechanism. The redistributions of Bax and cytochrome $c$ suggest that Bax moves to the mitochondria where it causes the release of cytochrome $C$, which might produce a cascade of events leading to DNA fragmentation. Apoptosis occurs at stage XII, mainly in metaphase spermatocytes. $C B$, an antiapoptotic molecule, is also highly expressed at the same stage and in the same type of cell. We suggest that $\mathrm{CB}$ overexpression might be a mechanism to prevent or reduce spermatogenic apoptosis caused by $\mathrm{Rb}$ rearrangements. It is quite possible that the ability of CB to prevent and maybe rescue cells from apoptosis could explain the subfertility in these mice. The knowledge of specific mechanisms controlling germ cell apoptosis could have particular importance for understanding some aspects of male infertility.

\section{Materials and Methods}

\section{Animals}

We used adult male laboratory mice (Mus musculus domesticus, CD1 strain; weight: 40 g) carrying the standard chromosome complement of $2 n=40$ acrocentric chromosomes, wildderived mice carrying $2 n=24$ chromosomes (M. m. domesticus, Milano II population, Mil II; Gropp et al. 1982, weight: $30 \mathrm{~g})$ and heterozygous animals $(2 n=32$; weight: $40 \mathrm{~g})$ obtained by crossing CD1 female mice with Mil II males. The mice were maintained according to the Guide for Care and Use of Laboratory Animals. Three 5-month-old male mice of each karyotype group were killed by cervical dislocation. Every effort was made to minimise the number of animals used and their suffering.

\section{Chemical reagents}

All reagents were purchased from Sigma Chemical Co. unless otherwise stated.

\section{Histology}

The right testis of each mouse was fixed in Bouin's fluid and embedded in paraffin wax. Five micrometre serial transverse cross sections were made for the subsequent co-localisation analyses. At least four serial sections of each testis were mounted on each glass slide. One slide was stained by the periodic acid-Schiff reaction and counterstained with haematoxylin to identify the stages of seminiferous epithelium according to Oakberg (1956).

\section{TUNEL assay}

For histological evaluation of apoptosis, the sections were processed with the TUNEL method, using an ApopTag Plus Peroxidase In Situ Apoptosis Kit (Chemicon-Millipore, Billerica, MA, USA), according to the manufacturer's instructions. Sections were permeabilised by incubation with proteinase $\mathrm{K}(20 \mu \mathrm{g} / \mathrm{ml})$ for $10 \mathrm{~min}$, and then exposed for 5 min to $3 \%(v / v) \mathrm{H}_{2} \mathrm{O}_{2}$ for endogenous peroxidase inhibition, incubated in the terminal deoxynucleotidyl transferase (TdT) labelling reaction mix for $1 \mathrm{~h}$ at $37^{\circ} \mathrm{C}$, washed in PBS, incubated with the anti-digoxigenin and finally developed with 3,3'-diaminobenzidine (DAB). Positive and negative controls were also set up. The positive controls were established using the slides contained in the same kit and following the manufacturer's instructions. For the negative controls, sections were processed without TdT enzyme in the labelling reaction mix. The sections were counterstained with $0.5 \%(\mathrm{w} / \mathrm{v})$ methyl green for $10 \mathrm{~min}$ at room temperature.

\section{Immunohistochemical analysis}

Serial sections were processed according to the avidin-biotinperoxidase complex method. Following deparaffinisation, sections were hydrated and incubated for $10 \mathrm{~min}$ in $0.5 \%(\mathrm{v} / \mathrm{v}) \mathrm{H}_{2} \mathrm{O}_{2}$ diluted in methanol to reduce endogenous peroxidase activity. After having been rinsed in PBS, the slides were incubated with normal bovine serum at $10 \%(\mathrm{v} / \mathrm{v})$ in PBS for 10 min to prevent non-specific binding of the primary antibody. Thereafter, the primary antibodies mouse anti-bovine $\mathrm{CB}$ monoclonal antibody (clone CB-955; Santa Cruz Biotechnology, Santa Cruz, CA, USA), rabbit anti-mouse Bax (P-19, polyclonal antibody, Santa Cruz Biotechnology) and purified mouse anti-mouse cytochrome $C$ monoclonal antibody (BD Pharmingen, Franklin Lakes, NJ, USA) were applied at a dilution of $1: 1000$ in PBS at $37^{\circ} \mathrm{C}$ for $1 \mathrm{~h}$. Later, the sections were washed thrice in PBS and then incubated with appropriate secondary biotinylated antibodies diluted in PBS. After $30 \mathrm{~min}$, the sections were incubated with peroxidaseconjugated streptavidin (Molecular Probes, Carlsbad, CA, USA) and developed with DAB (Dako, Glostrup, Denmark). The control sections were incubated using the same procedure but only with the secondary antibodies. Cytochrome $c$ and Bax immunoreacted sections were counterstained with haematoxylin. Sections were visualised using a Leica DM LB microscope and images were obtained with a Leica DC 180 Camera.

\section{Immunoblot analysis}

Western blot analysis was performed to detect the expression of $\mathrm{CB}$, cytochrome $\mathrm{C}$ and Bax proteins. The left testis of each mouse, freed from the albuginea membrane, was homogenised in PBS. The total protein suspension of each testis was centrifuged for $10 \mathrm{~min}$ at $13000 \mathrm{~g}$. The protein concentration of supernatants was measured using Bradford's method. Supernatants ( $10 \mu \mathrm{g} / \mathrm{sample})$ were mixed with loading buffer $(2 \% \mathrm{w} / \mathrm{v}$ SDS in Tris- $\mathrm{HCl}(\mathrm{pH}$ 8) containing $25 \% \mathrm{v} / \mathrm{v}$ glycerol, $1 \% \mathrm{v} / \mathrm{v} \beta$-mercaptoethanol and $0.1 \% \mathrm{v} / \mathrm{v}$ bromophenol blue). The mixture was denatured for $5 \mathrm{~min}$ at $95{ }^{\circ} \mathrm{C}$ and aliquots of $15 \mu \mathrm{l}$ homogenate were separated in $12.5 \% \mathrm{w} / \mathrm{v}$ SDSpolyacrylamide minigels. Gels containing the separated proteins were immersed in the transfer buffer $(25 \mathrm{mM}$ Tris-HCl, $192 \mathrm{mM}$ glycine, $0.05 \% \mathrm{w} / \mathrm{v}$ SDS and $20 \% \mathrm{v} / \mathrm{v}$ methanol). Nitrocellulose membranes $(0.2 \mu \mathrm{m})$ were blocked for $2 \mathrm{~h}$ with $3 \% \mathrm{w} / \mathrm{v}$ skimmed milk in PBT $(1 \times \mathrm{PBS}$ plus $0.05 \% \mathrm{v} / \mathrm{v}$ Tween20) and incubated for $1 \mathrm{~h}$ at $37^{\circ} \mathrm{C}$ with the primary antibodies at 1:1000 dilution ( $\mathrm{CB}$, cytochrome $\mathrm{C}), 1: 5000$ dilution 
(purified goat anti-human actin polyclonal antibody, Santa Cruz Biotechnology) or 1:500 dilution (Bax) in PBT with 1\% w/v BSA. After extensive washing with PBT, the membranes were incubated with anti-rabbit (Bax), anti-goat (actin) or antimouse (CB and cytochrome $c$ ) biotinylated antibodies for $1 \mathrm{~h}$ at $37^{\circ} \mathrm{C}$ using a $1: 2000$ dilution in PBT with $1 \% \mathrm{w} / \mathrm{v}$ BSA and then washed thoroughly. The appropriate Western Blot Amplification Module (Bio-Rad) and the Opti-4CN Substrate Kit (BioRad) were used, according to the manufacturers' instructions, for detection. Actin was used as a marker to normalise the relative expression of the other proteins. The band intensity was quantified by the Image J software (Wayne Rasband, NIH, Bethesda, MD, USA) in order to obtain the relative expression of proteins.

\section{Transmission electron microscopy}

Small pieces of seminiferous tubules were fixed by immersion in a mixture of $1.5 \%(\mathrm{v} / \mathrm{v})$ glutaraldehyde and $4 \%(\mathrm{v} / \mathrm{v})$ formaldehyde in $0.1 \mathrm{M}$ cacodylate buffer, and then treated with $1 \% \mathrm{w} / \mathrm{v}$ osmium tetroxide, dehydrated and embedded in Araldite at $60{ }^{\circ} \mathrm{C}$. For ultrastructural studies, thin sections were cut with a diamond knife on a Porter-Blum MT2 and JEOL JUM-7 ultramicrotome, counterstained with lead citrate and uranyl acetate, and examined in a Zeiss LEO 906E electron microscope.

\section{Statistical methods}

Four sections were selected at random from each testis for both the immunohistochemical studies and the TUNEL assay. At least nine transverse sections of seminiferous tubules for each epitope, TUNEL labelling or their combinations were randomly chosen and pictures were taken at $400 \times$ magnitude by two independent researchers in a blinded fashion. A cross section of a tubule was considered apoptotic when three or more TUNEL-positive cells were present within the seminiferous epithelium (Eaker et al. 2001). For each animal testis, 100 cross-sectioned tubules were scored to evaluate the frequency of the immunopositive or apoptotic sections. The percentage of positive cells for each epitope or TUNEL labelling was calculated taking into account the total number of cells per tubule section at the same stage of differentiation. Abercrombie's (1946) correction was applied to all cell counts. Two serial sections were processed with two different antibodies (CB and Bax, CB and cytochrome $c$ ) or with an antibody and TUNEL assay (CB and TUNEL) in order to compare and analyse the co-localisation of the different markers. Statistical significance between means of the different groups was assessed by the oneway ANOVA, followed by Bonferroni's post hoc test. A $P$ value $<0.05$ was considered statistically significant.

\section{Acknowledgements}

This work was supported by a Bilateral Grant 2005-2007 from MAE-SECYT (Italia-Argentina), funds from the Olympus Europa Foundation, Millipore France and Ministero dell'Università e della Ricerca FIRB 2005 (Dr Silvia Garagna) and from FONCYT (PICT 2005), CONICET (PIP (2005-2006) and SECYT (UNC 2006-2007) (Dr Nori Tolosa de Talamoni). Dr Nori Tolosa de
Talamoni is a Member of Career from CONICET (Argentina). Valeria Rodriguez is a recipient of a CONICET fellowship. The authors declare that there is no conflict of interest that would prejudice the impartiality of this scientific work.

\section{References}

Abercrombie M 1946 Estimation of nuclear population from microtome sections. Anatamoical Record 94 239-247.

Allan DJ, Harmon BV \& Kerr JFR 1987 Cell death in spermatogenesis. In Perspectives on Mammalian Cell Death, pp 229-258. Ed. CS Potten. Oxford: Oxford University Press.

Bellido T, Huening M, Raval-Pandya M, Manolagas SC \& Christakos S 2000 Calbindin- $\mathrm{D}_{28 \mathrm{k}}$ is expressed in osteoblastic cells and suppresses their apoptosis by inhibiting caspase-3 activity. Journal of Biological Chemistry $27526328-26332$.

Christakos S \& Liu Y 2004 Biological actions and mechanism of action of calbindin in the process of apoptosis. Journal of Steroid Biochemistry and Molecular Biology 89-90 401-404.

Coureuil M, Fouchet P, Prat M, Letallec B, Barroca V, Dos Santos C, Racine C \& Allemand I 2006 Caspase-independent death of meiotic and postmeiotic cells overexpressing p53: calpain involvement. Cell Death and Differentiation 13 1927-1937.

Eaker S, Pyle A, Cobb J \& Handel MA 2001 Evidence for meiotic spindle checkpoint from analysis of spermatocytes from Robertsonian-chromosome heterozygous mice. Journal of Cell Science 114 2953-2965.

Eaker S, Cobb J, Pyle A \& Handel MA 2002 Meiotic prophase abnormalities and metaphase cell death in MLH1-deficient mouse spermatocytes: insights into regulation of spermatogenic progress. Developmental Biology 249 85-95.

Eguchi J, Koji T, Nomata K, Yoshii A, Shin M \& Kanetake H 2002 Fas-Fas ligand system as a possible mediator of spermatogenic cell apoptosis in human maturation-arrested testes. Human Cell 15 61-68.

Francavilla S, D'Abrizio P, Rucci N, Silvano G, Properzi G, Straface E, Cordeschi G, Necozione S, Gnessi L, Arizzi M et al. 2000 Fas and Fas ligand expression in fetal and adult human testis with normal or deranged spermatogenesis. Journal of Clinical Endocrinology and Metabolism 85 2692-2700.

Francavilla S, D'Abrizio P, Cordeschi G, Pelliccione F, Necozione S, Ulisse S, Properzi G \& Francavilla F 2002 Fas expression correlates with human germ cell degeneration in meiotic and post-meiotic arrest of spermatogenesis. Molecular Human Reproduction 8 213-220.

Gropp A, Winking H, Redi C, Capanna E, Britton-Davidian J \& Noack G 1982 Robertsonian karyotype variation in wild house mice from RhaetoLombardia. Cytogenetics and Cell Genetics 34 67-77.

Hauffe HC \& Searle JB 1998 Chromosomal heterozygosity and fertility in house mice (Mus musculus domesticus) from Northern Italy. Genetics 150 1143-1154.

Inpanbutr N, Reiswig JD, Bacon WL, Slemons RD \& Iacopino AM 1996 Effect of vitamin D on testicular CaBP28K expression and serum testosterone in chickens. Biology of Reproduction 54 242-248.

Jahnukainen K, Crysis D, Hou M, Parvinen M, Eksborg S \& Soder O 2004 Increased apoptosis occurring during the first wave of spermatogenesis is stage-specific and primarily affects midpachytene spermatocytes in the rat testis. Biology of Reproduction 70 290-296.

Lee NPY, Leung KW, Wo JY, Tam PC, Yeung WSB \& Luk JM 2006 Blockage of testicular connexins induced apoptosis in rat seminiferous epithelium. Apoptosis 11 1215-1229.

Lizama C, Alfaro I, Reyes JG \& Moreno RD 2007 Up-regulation of CD95 (Apo-1/Fas) is associated with spermatocyte apoptosis during the first round of spermatogenesis in the rat. Apoptosis 12 499-512.

Luu KC, Nie GY, Hampton A, Fu GQ, Liu YX \& Salamonsen LA 2004 Endometrial expression of calbindin (CaBP)-d28k but not CaBP-d9k in primates implies evolutionary changes and functional redundancy of calbindins at implantation. Reproduction 128 433-441.

Mathiasen IS, Sergeev IN, Bastholm L, Elling F, Norman AW \& Jäätelä M 2002 Calcium and calpain as key mediators of apoptosis-like death induced by vitamin D compounds in breast cancer cells. Journal of Biological Chemistry 277 30738-30745. 
Merico V, Pigozzi MI, Esposito A, Merani MS \& Garagna S 2003 Meiotic recombination and spermatogenic impairment in Mus musculus domesticus carrying multiple simple Robertsonian translocations. Cytogenetic and Genome Research 103 321-329.

Mishra DP, Pal R \& Shaha C 2006 Changes in cytosolic $\mathrm{Ca}^{2+}$ levels regulate $\mathrm{BCl} 2-\mathrm{xS}$ and $\mathrm{BCl} 2-\mathrm{xL}$ expression in spermatogenetic cells during apoptotic death. Journal of Biological Chemistry $2812133-2143$.

Oakberg EF 1956 A description of spermatogenesis in the mouse and its use in analysis of the cycle of the seminiferous epithelium and germ cell renewal. American Journal of Anatomy 99 391-413.

Petre-Lazar B, Livera G, Moreno SG, Trautmann E, Duquenne C, Hanoux V, Habert R \& Coffigny H 2007 The role of p63 in germ cell apoptosis in the developing testis. Journal of Cell Physiology 210 87-98.

Pochet R, Blachier F, Malaisse W, Parmentier M, Pasteels B, Pohl V, Resibois A, Rogers J \& Roman A 1989 Calbindin-D28 in mammalian brain, retina, and endocrine pancreas: immunohistochemical comparison with calretinin. Advances in Experimental Medicine and Biology 255 435-443.

Rabinovitch A, Suarez-Pinzon WL, Sooy K, Strynadka K \& Christakos S 2001 Expression of calbindin-D(28k) in a pancreatic islet beta-cell line protects against cytokine-induced apoptosis and necrosis. Endocrinology 142 3649-3655.

Redi CA, Garagna S, Pellicciari C, Manfredi Romanini MG, Capanna E, Winking H \& Gropp A 1984 Spermatozoa of chromosomally heterozygous mice and their fate in male and female genital tracts. Gamete Research 9 273-286.

Redi CA, Garagna S, Hilscher B \& Winking H 1985 The effects of some Robertsonian chromosome combinations on the seminiferous epithelium of the mouse. Journal of Embryology and Experimental Morphology 85 1-19.

Russell LD 1999 Cell loss during spermatogenesis. In Male Sterility and Motility Disorders, pp 103-124. Eds S Hammamah, R Mieusset, F Olivennes \& R Frydman. New York: Springer.
Russell LD, Chiarini-Garcia H, Korsmeyer SJ \& Knudson CM 2002 Baxdependent spermatogonia apoptosis is required for testicular development and spermatogenesis. Biology of Reproduction 66 950-958.

Saunders PTK 2003 Germ cell-somatic cell interactions during spermatogenesis. Reproduction S61 91-101.

Sinha Hikim AP, Lue Y, Diaz-Romero M, Yen PH, Wang C \& Swerdloff RS 2003 Deciphering the pathways of germ cell apoptosis in the testis. Journal of Steroid Biochemistry and Molecular Biology 85 175-182.

Vera Y, Diaz-Romero M, Rodriguez S, Lue Y, Wang C, Swerdloff R \& Sinha Hikim AP 2004 Mitochondria-dependent pathway is involved in heatinduced male germ cell death: lessons from mutant mice. Biology of Reproduction 70 1534-1540.

Wallace BM, Searle JB \& Everett CA 2002 The effect of multiple simple Robertsonian heterozygosity on chromosome pairing and fertility of wild-stock house mice (Mus musculus domesticus). Cytogenetic and Genome Research 96 276-286.

Walters MR, Bruns ME, Carter RM \& Riggle PC 1991 Vitamin D independence of small calcium-binding proteins in nonclassical target tissues. American Journal of Physiology 260 794-800.

Wasserman RH \& Taylor AN 1966 Vitamin $D_{3}$-induced calcium-binding protein in chick intestinal mucosa. Science 152 791-793.

Yuan W, Leisner TM, McFadden AW, Clark S, Hiller S, Maeda N, O'Brien DA \& Parise LV 2006 CIB1 is essential for mouse spermatogenesis. Molecular and Cellular Biology 26 8507-8514.

Received 18 October 2007

First decision 2 January 2008

Revised manuscript received 8 February 2008

Accepted 25 February 2008 